\title{
Paradigmas pictóricos en la metaforología temprana de Hans Blumenberg1
}

\author{
Pictorical Paradigms in early \\ Hans Blumenberg's metaforology
}

\author{
Alberto Fragio \\ Eidgenössische Technische Hochschule Zürich \\ Chair for Science Studies \\ albfragio@gmail.com
}

Recibido: 21/07/2010

Aceptado: 20/06/2011

\section{Resumen}

Los estudios especializados en la obra de Hans Blumenberg [1920-1996] han prestado poca atención a las relaciones de la metaforología con la historia del arte. El interés de Blumenberg por temas estéticos y pictóricos es ya patente en sus primeras publicaciones, así como en diversos textos de madurez. En el presente artículo tomamos en consideración este ámbito específico de la obra blumenberguiana. Atendemos en particular a la incidencia de varias tradiciones pictóricas en la temprana gestación de su metaforología.

Palabras clave: metaforología, mímesis, fauvismo, El Greco, Giulio Clovio, Parmigianino, Rembrandt.

\footnotetext{
1 Este trabajo ha sido posible gracias a una beca postdoctoral del Gobierno suizo, disfrutada en la Eidgenössische Technische Hochschule Zürich durante el curso 2011/2012. Me gustaría expresar mi agradecimiento al Prof. Michael Hagner, a los miembros de la Chair for Science Studies (ETH-Zürich) y al Grupo permanente de Epistemología histórica e Historia de las emociones del Consejo Superior de Investigaciones Científicas (CSIC-Madrid). Esta investigación se ha beneficiado además del proyecto internacional "Epistemología histórica: comunidades y estilos emocionales en los siglos XIX y XX”, financiado por el Ministerio de Ciencia e Innovación de España (FFI2010-20 876) para el periodo 2011-2014.
} 


\begin{abstract}
Specialized studies on Hans Blumenberg's works have paid little attention on relations between metaphorology and art history. Blumenberg's interest on aesthetic and pictorial topics are already in his very first publications, but also in his later works. In this paper we consider this specific field, particularly regarding the incidence of various pictorial traditions in early gestation of Blumenberg's metaphorology.
\end{abstract}

Keywords: Metaphorology, mimesis, Fauvism, El Greco, Giulio Clovio, Parmigianino, Rembrandt.

\title{
Sumario
}

1. El encuentro de Clovio y El Greco en Roma

2. El hombre moderno y la ruptura de la mímesis pictórica: de Parmigianino a Paul Klee

3. La ruptura de la mímesis en Raoul Dufy y Franz Marc

4. Paul Klee y la renovación de la mímesis

5. Una comprensión fauve de la metaforología temprana

6. Excurso: el fauvismo en perspectiva histórica

7. El fauvismo como metaforología estética del sentido

8. Metáfora y mito en el origen de los conceptos metafísicos

9. Luz y palabra en la metafísica metafórica cristiana

En forma de un realce e interpretación de elementos expresivos artísticos, la tarea y metódica de la metaforología puede, pues, llevar también más allá de la esfera histórico-objetiva. ${ }^{2}$

(Hans Blumenberg, Paradigmen zu einer Metaphorologie)

\section{El encuentro de Clovio y El Greco en Roma}

En uno de los últimos libros de Hans Blumenberg, Die Sorge geht über den Flu $\beta$ [1987], se recoge el encuentro en Roma de Giulio Clovio [1498-1578] y E1 Greco [1541-1614]:3

2 "In Gestalt einer Heraushebung und Interpretation von Aussageelementen der Kunst mag also die Aufgabe und Methodik der Metaphorologie auch über die historische Gegenstandssphäre hinaus führen" (PM 24-5, 63).

3 Nos referimos en particular al texto «In Rom, etwas später». Este breve texto formaba parte de «Verfehlungen. Glossen zu Anekdoten», publicado inicialmente en Akzente, 5, 1984, pp. 390-396. 
En un día de primavera de $1750^{4}$ el pintor miniaturista de origen croata Giulio Clovio visita a un trabajador de grandes lienzos, a su colega Theotokópoulos, el principal discípulo de Tiziano, por su origen denominado El Greco. Va a buscarle para dar un paseo por la ciudad bajo el primer sol del año, sol que, como escribirá en una carta no exenta de censura, 'podría alegrar a cualquiera'. ¡Qué sorpresa cuando pisa el taller del Greco! Describe así su estado: 'Las cortinas estaban tan espesamente corridas ante las ventanas que apenas se podian reconocer los objetos'. El maestro estaba sentado extrañamente ausente sobre una silla: 'No trabajaba, tampoco dormía'. De la invitación a seguirle fuera, no quiere saber nada. Como excusa habría dicho algo que Clovio aceptó como disculpa: la luz del día estorbaba su luz interior $(d S 174,135) .^{5}$

Con el propósito de caracterizar mejor este encuentro, Blumenberg alude a una segunda carta que Clovio envió a su protector, el Cardenal Alessandro Farnese, en la que le rogaba que diera alojamiento en su palacio al pintor recién llegado a Roma: "a través de esta carta, El Greco parece ser alguien que no se las arregla bien con la realidad de la capital del mundo" (dS 174, 136). La intervención providencial de Clovio "prepara la oscura escena del taller, como alejamiento de toda belleza del mundo exterior" (dS 174, 136).

En este encuentro se reunían las condiciones para una de esas "conversaciones cumbre" ["Gipfelgespräche"] (dS 184-96, 143-52) que tanto gustaba a Blumenberg reconstruir, con el añadido de que dichos interlocutores eran, en el fondo, hombres pertenecientes a épocas y sensibilidades distintas. Sin embargo, la falta de información fidedigna sólo le permitía a Blumenberg esbozar a grandes rasgos la escena, todo lo demás debía ser objeto de una libre variación. Esta circunstancia propicia en Blumenberg una reflexión de lo más reveladora sobre la "luz interior" del Greco:

\footnotetext{
Algunos años después Lea Ritter Santini [1928-2008] emplazó a Blumenberg a que lo publicara de nuevo en el volumen 10 de la revista Dichtung und Sprache, auspiciada por la Deutsche Akademie für Sprache und Dichtung. No en vano el ámbito de especialización de Santini era la iconología literaria en relación con la historia de las ideas, el estudio histórico de las metáforas y la iconografía. Santini fue íntima amiga y colega de Blumenberg en la Universidad de Münster, donde ejercía como profesora de literatura alemana y literatura comparada.

4 Evidentemente está equivocada la fecha del encuentro entre Clovio y El Greco que figura en el artículo original de Blumenberg, así como en todas sus traducciones posteriores. Con seguridad se trata de un error tipográfico producido por la inversión de los números internos de la cifra, del 5 y el 7. El encuentro habría de producirse en 1570, y no en 1750.

5 Adopto las siglas de González Cantón, C., La metaforología de Blumenberg como destino de la analítica existencial, Universidad Complutense de Madrid, 2004, pp. 378-80. Modo de citación con siglas: entre paréntesis y en cursiva se indica la abreviatura acompañada por la página del original alemán. Tras una coma le sigue en redonda la página correspondiente de la traducción española, si la hay, o de alguna otra traducción en un idioma diferente al español. Por ejemplo: $(H 785,644)$. Cuando no se ha tenido acceso al texto original, tan sólo se indica la paginación en letra redonda de la traducción utilizada, antecedida por una coma. Por ejemplo: $(B i G, 129)$. En el caso contrario, cuando sólo se disponía del texto original, se ha indicado la página en cursiva después de la abreviatura, ambos en cursiva y sin coma. Por ejemplo: (Lt 120). En la relación bibliográfica final figuran las traducciones empleadas.
} 
Aunque hablar de luz interior es hacer uso de una metáfora central de la metafísica cristiana, esa expresión ya no puede ser remitida a un conflicto religioso. No es la luz de la Gracia la que estaría contra la de la creación. La luz interior que se pone en peligro por la luz exterior es el mundo propio del pintor, alzado contra el mundo ajeno del Dios de ahí fuera, que a la sazón ilumina de nuevo festivamente su naturaleza. De esto no quiere ni puede hacer caso el troglodita retirado a la penumbra, autor de la primera gran deformación de la naturalidad. En tanto que no invoca a algo así como su derecho creativo, al posterior 'genio', o a la 'creatividad', sino que habla de una luz interior, se rodea de una irrebatibilidad que elimina el aspecto chocante de su expectante estado. El complaciente visitante está extrañado por eso que está alejado de su propio tipo de artesanía, que requiere la mejor luz exterior para consagrarse al más pequeño detalle. No ha logrado su fin y no ha reconocido el del otro; pero toma esto como una de las rarezas con las que se había empezado a contar en este medio ( $d S$ 174-5, 135-6).

Parece plausible que Blumenberg hubiera tenido noticia del encuentro de Clovio y El Greco a través de un libro de Erwin Panofsky [1892-1968], titulado Idea. Ein Beitrag zur Begriffsgeschichte der älteren Kunsttheorie [1924].6 Blumenberg se refiere por extenso a este libro en su artículo de 1964 "El concepto de realidad y la posibilidad de la novela" [1964] ( $W b M 17,38$, nota 10), en particular al hilo del problema de la pervivencia del platonismo durante el Renacimiento. Así resumía Panofsky el contenido y el marco de discusión de su libro en el breve prólogo que acompañaba a la primera edición:

El presente estudio está en estrecha relación con una conferencia pronunciada por el profesor E. Cassirer en la Biblioteca Warburg, "La idea de lo Bello en los Diálogos de Platón", que aparecerá en el segundo volumen de las Conferencias de la Biblioteca Warburg. Nuestra investigación ilustrará el desarrollo histórico de ese concepto, cuyo valor sistemático puso de relieve la conferencia de Cassirer. El deseo de ambos autores era que esta conexión se manifestase también en la publicación, pero el presente estudio -sobre todo por la añadidura de notas en parte aumentadas en pequeñas digresiones y por los extractos de fuentes, en nuestro caso imprescindibles- se ha hecho demasiado extenso para tener cabida en las Conferencias de la Biblioteca Warburg. Por ello, el abajo firmante debe limitarse a remitir al lector a la conferencia mencionada anteriormente, agradeciendo de todo corazón al profesor Cassirer sus múltiples palabras de aliento y su preciosa y generosa ayuda. ${ }^{7}$

En el mencionado artículo de 1964, Blumenberg estaba interesado en este intercambio entre Cassirer y Panofsky ${ }^{8}$ para su revisión del dictum clásico - platónico-

\footnotetext{
6 Panofsky, E., Idea. Contribución a la historia de la teoría del arte [1924], trad. esp. María Teresa Pumarega, Madrid, Cátedra, 1989.

7 Ibidem., p. 9.

8 Para los detalles del debate entre Cassirer y Panofsky véase el libro de Ferretti, S., Il demone della memoria. Simbolo e tempo storico in Warburg, Cassirer, Panofsky, Marietti, Casale Monferrato, 1984,
} 
de acuerdo con el cual los poetas son unos mentirosos. En opinión de Blumenberg, "la historia de la literatura occidental puede ser resumida como un continuo debate con este dictum" ( $W b M 9,29)$. Pero no creemos oportuno entrar aquí en esta cuestión. Nos limitamos a señalar que en la primera edición del libro de Panofsky, la de 1924, se daba cuenta del encuentro entre Clovio y El Greco. Sin embargo, y curiosamente, en la edición de 1959 Panofsky había suprimido en exclusiva ese pasaje:

[Esta segunda edición] no difiere de la primera más que en la corrección de numerosos errores tipográficos y de toda índole, sobre todo, en la eliminación del último párrafo del capítulo 'El Manierismo' y de la nota 239 referente a él; ello se debe a que la noticia recogida por Giulio Clovio sobre un encuentro con El Greco y publicada luego por Hugo Kehrer, a la que hacía referencia ese párrafo, ha resultado ser una falsificación de carácter 'patriótico'.9

No acaba de quedar claro cuál de las dos versiones había utilizado efectivamente Blumenberg, aunque nos consta que supo de la existencia de ambas ( $W b M 17$, 38). A pesar de todo, el único especialista al que en realidad se refirió Blumenberg en su artículo de Die Sorge geht über den Flu $\beta$ no era Hugo Kehrer o el propio Panofsky, sino Carl Justi [1832-1912] quien a su vez hubo escrito una monografía sobre la estética de Platón, discutida copiosamente por Cassirer y Panofsky en la Warburg-Haus, y que llevaba por título Die ästhetische Elemente in der platonischen Philosophie [1860]. ${ }^{10}$ No obstante, Blumenberg sólo se refería a Justi como aquél que había descubierto la identidad del pintor implícitamente aludido por Clovio en su carta de recomendación al cardenal Farnese, y no como experto en estética platónica. Justi había acertado a desvelar que el "discepolo di Titiano"11 allí mencionado era, en efecto, El Greco.

Con independencia de estos pormenores, lo que nos interesa es resaltar la ejemplaridad del caso para ilustrar intuitivamente la temprana metaforología blumenberguiana de la luz, la verdad y la caverna $(L a M, P M, D d H)$, en especial con relación a la metafísica metafórica del Cristianismo medieval. Para ello contamos con un retrato 12 que El Greco hizo de Clovio en torno a 1571 -un año después del encuen-

pp. 143-75. Se puede ver también Stocks, J. L., «Review: The Warburg Library», The Classical Review, vol. 40, n. ${ }^{\circ} 2,1926$, p. 76.

9 Panofsky 1989, op. cit. (nota 6), p. 11.

10 Silvia Ferretti se ha ocupado abundantemente de Justi en relación con Cassirer y Panofsky. Véase su Il demone della memoria, op. cit. (nota 8), pp. 148-53. Véase también Karin Hellwig, «Investigaciones sobre arte español en la Kulturwissenschaftliche Bibliothek Warburg de Hamburgo. La estancia de Fritz Saxl en Madrid en 1927», Anales de Historia del Arte, 18, Madrid, pp. 216-8 y 221 , junto con las notas 9,10 y 12

11 Bray, X. y Olivier, L., «Chronology» en David Davies (ed), El Greco, National Gallery Company, London, 2003, p. 32.

12 Para los retratos de El Greco véase el estudio de Davies, D., «El Greco’s Portraits: The Body Natural and the Body Politic» en David Davies (ed), El Greco, ibidem, pp. 250-61. 
tro recogido por Blumenberg-durante su estancia en el palacio Farnese, y en el que se nos hace partícipes de una de esas escenas tenebrosas a las que El Greco era inclinado tanto en su vida como en su obra:

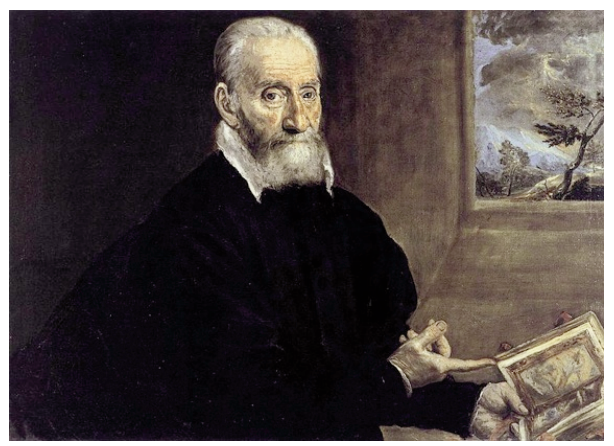

Figura 1. El Greco, Retrato de Clovio, c. 1571

En este cuadro se representa a Giulio Clovio con su obra maestra, Il Lezionario Farnese [1546].13 De una espesísima oscuridad emerge en primer plano el pintor de miniaturas, sosteniendo con su mano izquierda el códice que el Cardenal Farnese le encargó ilustrar, mientras que con el índice de su mano derecha señala con autoridad las dos escenas de contenido bíblico que en él se muestran, correspondientes, respectivamente, a "Dios padre creando el Sol y la Luna" (folio 59v) y "La Sagrada Familia" (folio 60r). ${ }^{14}$ De este modo describe la historiadora del arte Antonina Vallentin la pintura ejecutada por El Greco:

10 Silvia Ferretti se ha ocupado abundantemente de Justi en relación con Cassirer y Panofsky. Véase su Il demone della memoria, op. cit. (nota 8), pp. 148-53. Véase también Karin Hellwig, «Investigaciones sobre arte español en la Kulturwissenschaftliche Bibliothek Warburg de Hamburgo. La estancia de Fritz Saxl en Madrid en 1927», Anales de Historia del Arte, 18, Madrid, pp. 216-8 y 221 , junto con las notas 9,10 y 12

11 Bray, X. y Olivier, L., «Chronology» en David Davies (ed), El Greco, National Gallery Company, London, 2003, p. 32.

12 Para los retratos de El Greco véase el estudio de Davies, D., «El Greco’s Portraits: The Body Natural and the Body Politic» en David Davies (ed), El Greco, ibidem, pp. 250-61.

13 Clovio, G., Il Lezionario Farnese: Commentario al Codice, edición a cargo de Jonathan J. G. Alexander, Modena, Panini, 2009. El manuscrito original está celosamente custodiado en la Pierpont Morgan Library de Nueva York. Para más detalles véase Smith, W., The Farnese Hours, George Braziller, New York, 1976. Reseñado a su vez por Carroll, E. A., en The Art Bulletin, vol. 61, n. ${ }^{\circ}$ 1, 1979, pp. 136-41.

14 Un breve análisis del tema de la Sagrada Familia en Giulio Clovio, con amplio repertorio bibliográfico, en Rowlands, E. W., "A Newly Discovered Holy Family Drawing by Giulio Clovio», Master Drawings, vol. 23, n. ${ }^{\circ} 1,1985-6$, pp. 31-6. 
[A El Greco] le da mucha pena porque sabe que en ese punto [de su vida] un hombre de semejante renombre es indispensable para él. Le pinta como el modelo quiere ser pintado, a la manera de aquel Tiziano que tanto admira, tonalidad de negro y de blanco, fondo gris dorado. Le pinta también con esa tranquila autoridad de un hombre que ha sido cubierto de honores por sus méritos. [...] Su mirada es la de alquien que ha seguido su propio camino con paciencia y tenacidad, también con desenvoltura. 15

A través de la ventana se puede observar un tormentoso paisaje azotado por el viento, un inhóspito bosque en el que se levanta una escarpada cadena montañosa. El paisaje parece concebido para resaltar la presencia impertérrita y grave de Clovio, así como la iluminadora creación que porta entre sus manos, subrayada a su vez por una calculada y efectiva retórica gestual. Tanto la visión ofrecida por la ventana como la del libro abierto, poseen una fuerte luz que contrasta dramáticamente con la sombra impenetrable y cavernosa en la que se disuelve el cuerpo del miniaturista. Nos hallamos ante una triple alegoría: de la creación, de la revelación y de la salvación. Esta plural alegoría encuentra su expresión gracias a una relativamente simple iconografía a base de luces y sombras, que constituye, por otro lado, una excelente reelaboración pictórica de la tradición metafórica de la verdad como luz, de la que Blumenberg se ocupa en su artículo de 1957, "La luz como metáfora de la verdad: en el estadio previo a la formación de los conceptos filosóficos" ( $L a M$ 432-47), que más adelante tendremos ocasión de examinar.

Según Antonina Vallentin, Clovio había recibido por aquel momento la invitación de Felipe II de formar parte de su corte en el Real Monasterio de El Escorial, en calidad de pintor oficial del rey español. Sin embargo, "el hombre, ya anciano, que habia venido de tan lejos, no tiene ganas ni de viajar ni de servir a un nuevo patrono. A sus 71 años ha fatigado demasiado sus ojos por un trabajo minucioso [...], se lamenta de su vida y de sus manos debilitadas". 16 De hecho, es bastante probable que ambos pintores se conocieran por primera vez con motivo de una visita a Venecia que Clovio hizo por razones de salud. A esta ciudad "[...] había llegado con el propósito de ser tratado por un prestigioso médico [...]"17, y en ella se encontraba un Greco en ciernes aprendiendo el arte de su gran maestro Tiziano. 18

\footnotetext{
15 Vallentin, A., El Greco, Paris, Éditions Albin Michel, 1954, p. 66. Ésta y las otras citas de Vallentin que siguen a continuación son traducciones nuestras.

16 Ibidem, p. 65.

17 Ibidem, p. 63.

18 Una parte considerable de la labor historiográfica del propio Panofsky ha estado dedicada a Tiziano. Es de mucho interés a este respecto su ensayo «El movimiento neoplatónico en Florencia y el norte de Italia (Bandinelli y Tiziano)» recogido en sus Estudios de iconología [1939], trad. esp. Bernardo Fernández, Madrid, Alianza Editorial, 2004, pp. 189-238. Dedicó también varios capítulos y apéndices al análisis de algunas de las pinturas de Tiziano en su magnífico Hercule à la croisée des chemins et autres matériaux figuratifs de l'antiquité dans l'art plus récent [1930], trad. fr. Danièle Cohn, Paris, Flammarion, 1999, en especial los capítulos «Un allégorie de Titien. Ses relations avec la Prudence»,
} 
Vallentin también nos da más detalles de la llegada del Greco a Roma, acaecida en torno al año 1569:

Llevó consigo varios cuadros pintados en Venecia y también un autorretrato, lamentablemente desaparecido, pero que habría sido la verdadera revelación de su juventud. Giulio Clovio no era el único en ser impresionado. Como él mismo escribe en su intervención a favor del Greco, y no sin un punto de desprecio hacia sus colegas ["confrères'] romanos, ese retrato 'fa stupire tutti questi pittori di Roma'.19

Clovio le pide al Cardenal Farnese que lo tenga "bajo la sombra de Vuestra Ilustrísima y Reverendísima Señoría":20

No pide para su protegido más que una habitación en el palacio, sin otros medios de subsistencia ('senza spesa altra da vivere'). Además la solicita 'para poco tiempo' [...]. Clovio sabe que un favor de ese género no debe comportar ninguna molestia a un hombre siempre ocupadísimo, de tal modo que no vale la pena que tome él mismo las disposiciones necesarias. Bastaría con que -le escribe- avisara a su mayordomo Ludovico para que estableciera a su protegido en una habitación del palacio, no importa cuál. Concluye asegurando al Cardenal que esa sería 'una acción virtuosa digna de Vd.' ('un opera virtuosa digna di Lei'). ${ }^{21}$

Según Vallentin, "la estancia del Greco en Roma comenzó con esta humilde súplica de un hombre influyente en la época, pero que sólo por su intervención habia sido salvado del olvido. Gracias a Giulio Clovio, El Greco tuvo éxito en el centro intelectual de su tiempo".22

No obstante, lo cierto es que ni El Greco tuvo tanto éxito en Roma ni la trascendencia histórica de Clovio queda reducida a esta labor puntual de mediación. Al cabo de un año, el Cardenal expulsó al Greco del palacio. En una carta fechada el 6 de julio de 1572, El Greco le preguntaba a Farnese el motivo del desalojo, defendiendo a ultranza su inocencia ante cualquier acusación falaz que se hubiera podido levantar en su contra. ${ }^{23}$ Ya en 1576, cinco años después de haber realizado el

pp. 19-24 y «Pour l'interpretation de L'Amour sacré et l'Amour profane de Titien», pp. 173-79. Véase además el capítulo 4 de El significado de las artes visuales [1955], trad. esp. Nicanor Ancochea, Madrid, Alianza Editorial, 1987, pp. 171-94. Pero su obra de referencia sobre este pintor es Tiziano. Problemas de iconografía [1969], trad. esp. I. Morán García, Madrid, Akal, 2003. Un ensayo biográfico de la vida y obra de Tiziano en las pp. 25-46. Por lo demás, ni que decir tiene, la literatura especializada sobre Tiziano es inmensa.

19 Vallentin 1954, op. cit. (nota 15), p. 67.

20 Ibidem, p. 68.

21 Ibidem.

22 Ibidem.

23 Bray, X. y Olivier, L., «Chronology» en David Davies (ed), El Greco, London, National Gallery Company, 2003, pp. 32 y ss. 
retrato de Clovio, El Greco ponía rumbo a España con el objetivo último de trabajar al amparo de Felipe II, el mismo monarca que Clovio hubo de rechazar. Y ni siquiera allí las cosas fueron fáciles. Su cuadro El Martirio de San Mauricio, realizado para El Escorial, no fue del agrado del rey español, y El Greco quedó fuera del selecto círculo de artistas palaciegos. Tras su estrepitoso fracaso decidió instalarse definitivamente en Toledo, en donde no le faltaron los encargos. A esta etapa de su vida pertenece la Vista de Toledo, una pintura abiertamente "antimimética" que anticipaba en más de doscientos años las vanguardias artísticas de finales del siglo XIX y comienzos del XX, que constituyen -como trataremos de mostrar más adelantealgunos de los principales paradigmas pictóricos de la metaforología temprana de Blumenberg.

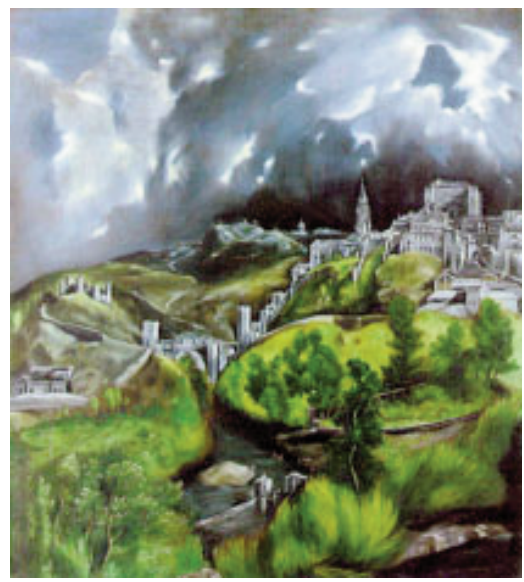

Figura 2. El Greco, Vista de Toledo, 1596-1600

\section{El hombre moderno y la ruptura de la mímesis pictórica: de Parmigianino a Paul Klee}

En noviembre de 1956 Blumenberg pronunció una asombrosa conferencia en la Philosophische Fakultät der Universität München, con el título "Imitación de la naturaleza'. Acerca de la prehistoria de la idea del hombre creador" [1957] (NdN 55-103, 73-114). En ella encontramos esta enigmática declaración:

¿No está empeñado el hombre moderno, desde hace ya mucho tiempo, en ser algo 'creador', y no contrapone la construcción a la naturaleza? Y desde que Parmigianino pintara en 1523 su autorretrato partiendo de la imagen desfigurada de un espejo convexo -no conservando y sublimando lo natural en lo artístico, sino quebrándolo y transformándolo-, se articula cada vez con más vigor en la obra de arte la firma de un creador que es consciente de su potencia $(N d N 56,74)$. 
Blumenberg se refiere al pintor italiano Girolamo Francesco Maria Mazzola [1503-1540], usualmente conocido como Parmigianino. ${ }^{24}$ Antes de salir de Parma hacia Roma con el propósito de hacer fortuna en la gran ciudad imperial, el joven pintor consideró oportuno seleccionar cuatro de sus mejores pinturas a modo de tarjeta de visita. Éstas no sólo habían de mostrar fehacientemente lo elevado de su arte, sino que además debían transigir con el requisito práctico de ser fáciles de transportar. ${ }^{25}$ Una de estas obras, según el testimonio de Giorgio Vasari, ${ }^{26}$ un historiador del arte del siglo XVI, era precisamente el autorretrato al que alude Blumenberg, ${ }^{27} \mathrm{y}$ que mostramos a continuación:

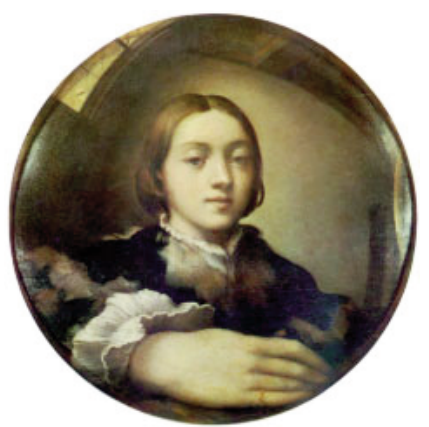

Figura 3. Parmigianino, Autorretrato ante un espejo convexo, 1524

El propio Vasari nos ha dado una descripción de esta pintura en su célebre $L e$ Vite dei più eccellenti scultori, pittori e architetti [1568]:

[...] para investigar las sutilezas del arte, un día [Parmigianino] intentó retratarse a sí mismo mirándose en un espejo de barbero [...]. Procediendo de tal modo, observando las extravagancias causadas por la redondez del espejo, decidió imitar cada cosa según su caprichosa forma [...]. Puesto que todos los objetos próximos al espejo crecían, mientras que los lejanos menguaban, nos ofreció una mano dibujada un tanto grande, como aquélla reflejada en el espejo, tan bella que parecía más que verdadera; y dado

\footnotetext{
24 Un somero análisis las pinturas y dibujos de Parmigianino en Franklin, D., The Art of Parmigianino, New Haven and London, Yale University Press, 2003, pp. 1-30 y 31-50. Tres de los temas prevalentes de la obra de Parmigianino son las narraciones mitológicas, los retratos y las pinturas de devoción sacra. El lector interesado podrá encontrar un estudio exhaustivo en el trabajo de Chiusa, M. C., Parmigianino, Milano, Electa, 2001, pp. 35-70, pp. 71-113 y 113-82, respectivamente. Para un análisis específico de los temas sacros véanse los estudios reunidos en Baumstark, R. (ed.), Parmigianino. Die Madonna in der Alten Pinakothek, Berlin, Hatje Cantz, 2007.

25 Franklin 2003, op. cit. (nota 24), p. 11.

26 Ibidem.

27 Aunque sea un detalle muy menor, en la mayor parte de las fuentes suele figurar como fecha del autorretrato 1524, y no 1523, como indica Blumenberg.
} 
que Francesco gozaba de un buena presencia, con un rostro y un aspecto graciosos, más de ángel que de hombre, su imagen en ese cuadro se antojaba un asunto divino. ${ }^{28}$

En este autorretrato, Parmigianino se representó a sí mismo en su estudio, engalanado con las mejores ropas y luciendo un llamativo anillo en la mano derecha, con el que daba a entender su buena extracción social. ${ }^{29}$ A uno de sus lados se puede identificar un caballete, así como parte de otro espejo, revelador del interés del joven artista por la autoobservación. Si bien la mano derecha está anormalmente alargada, lo cierto es que su rostro está perfectamente centrado en la composición y no sufre las distorsiones del espejo convexo.

En último término, resulta difícil saber si Parmigianino desplegaba en su autorretrato una cínica insistencia en sí mismo, como reelaboración tardía y quizá amarga del mito de Narciso - ahora un Narciso proveniente de una familia modesta, pese al anillo y la ropa- o si por el contrario su pintura no pasaba de un singular juego visual dispuesto a los efectos de persuadir a los mecenas y coleccionistas romanos de su gran talento como pintor. Sea como fuere, lo que aquí nos interesa es el valor ejemplar que le otorga Blumenberg a la hora de mostrar el gran momento de ruptura de la mímesis platónica, es decir, de la concepción según la cual el arte es una imitación de la naturaleza $(N d N 55,73) .{ }^{30} \mathrm{El}$ nuevo arte surgido con la Modernidad $\mathrm{y}$, según Blumenberg, cabalmente representado por el manierismo de Parmigianino, ya no pretendería asemejarse a la naturaleza, sino que más bien sería la "autocomprobación y testimonio de su genuina potencia de ser" (NdN 56, 74), ligada además "a la conciencia del carácter absoluto del saber artístico" (NdN 56, 74). Con el arte moderno quedaría descubierta la infinitud en el seno de lo fáctico, como la experiencia de un inmenso horizonte de posibilidades que pueden ser transitadas a

\footnotetext{
28 Vasari, G., Le Vite dei più eccellenti scultori, pittori e architetti, Roma, ed. Firenze, 1568, vol. III, 1991, p. 778, ed. crítica a cargo de M. Marini; véase también G. Vasari, Le Vite de più eccellenti architetti, pittori, et scultori italinai, da Cimabue, insino a' tempi nostri, ed. L. Torrentino, Firenze, 1550, vol. II, a cargo de L. Bellosi e A. Rossi, Einaudi, 1986 y 1991, p. 793. Existe una traducción española parcial a cargo de María Teresa Méndez Baiges y Juan María Montijano García: Vasari, G., Las vidas de los más excelentes arquitectos, pintores y escultores italianos desde Cimabue a nuestros tiempos (Antología), Madrid, Editorial Tecnos, 2006. La traducción del pasaje citado es nuestra.

29 Franklin 2003, op. cit. (nota 24), p. 12.

30 Estas son las referencias bibliográficas sobre historia del arte que utilizó Blumenberg para el texto de su conferencia: Katalog der Ausstellung [catálogo de la exposición] Der Triumph des europäischen Manierismus, Rijksmuseum, Amsterdam, 1955, n. ${ }^{\circ}$ 88; Werner Hofmann, «'Manier' und 'Stil' in der Kunst des 20. Jahrhunderts», Studium Generale, 8, Berlin, 1955; Werner Haftmann, Malerei im 20. Jahrhundert, München, Prestel Verlag, 1954. Albert Skira (ed), Geschichte der modernen Malerei. Fauvismus und Expressionismus. Van Gogh, Gaugin, Matisse, Marquet, Vlaminck, Derain, Dufy, Friesz, Braque, Modersohn, Kirchner, Schmidt-Rottluff, Kandinsky, Jawlensky, Munch, Holder, Ensor, Rouaut, Nolde, Weber, Kokoschka, Chagall, Soutine, Ginebra, Skira Verlag, 1950; Werner Haftmann, Paul Klee. Wege bildnerischen Denkens, München, Prestel Verlag, 1950; Paul Klee, Über die moderne Kunst, Berna, Benteli, 1945 (trad. esp. Teoría del arte moderno, Buenos Aires, Calden, 1976).
} 
voluntad, y que van mucho más allá de una nuda y empobrecedora emulación de lo dado. Frente a la estrechez de lo existente, la Modernidad apela a la inagotable potencialidad de lo que cabe realizarse.

En su argumentación, Blumenberg se apoya en el historiador del arte Werner Hofmann, a quien con alguna probabilidad habría tenido oportunidad de conocer personalmente. ${ }^{31}$ En las investigaciones sobre el arte moderno desarrolladas por Hofmann -y por moderno se entiende ahora el arte de la segunda mitad del siglo XIX y principios del XX-, se había topado con el problema de la disolución del "arte figurativo", 32 es decir, del arte que perdía su contenido representacional y se volvía "abstracto". ${ }^{33}$ Ello planteaba la dificultad teórica e historiográfica de establer una solución de continuidad entre un tipo y otro de arte. Para resolver esta cuestión, Hofmann no dudaba en hacer uso de sus excelentes conocimientos filosóficos, en particular del pensamiento de Ernst Cassirer. ${ }^{34}$ Hofmann recurría así en uno de sus textos a la filosofía de las formas simbólicas, 35 con la que aspiraba a dar una res-

${ }^{31}$ Es de notar que en la década de los 50 ambos autores publicaban en Studium Generale. Para el caso de Blumenberg, la mayor parte de sus artículos tempranos verán la luz en esta revista berlinesa. Por otro lado, al poco de que Blumenberg dejara la Universidad de Hamburgo para irse a la de Gießen, Hofmann era nombrado director del Hamburger Kunsthalle. Además ambos conocían la WarburgHaus, de cuya Kulturwissenschaftliche Bibliothek Blumenberg habría obtenido materiales para sus trabajos. Así al menos lo hizo constar públicamente un representante de la Universidad de Hamburgo en el solemne acto de apertura del Internationale Blumenberg-Konferenz. Hans Blumenberg und die Herasuforderung 'Menschliches nicht verloren zu geben'. Vernunft-Imagination-Erinnerung, un congreso dedicado monográficamente al análisis de la obra de Blumenberg, y que se celebró precisamente en la Warburg-Haus y la Gästehaus der Universität Hamburg entre el 13 y el 16 de noviembre de 2008. Sin embargo, la vinculación efectiva de Blumenberg con la Warburg-Haus es más que dudosa. En realidad, la mayor parte de los fondos de la Kulturwissenschaftliche Bibliothek habían sido depositados en 1933 en la University College London, con motivo de la emergencia del nazismo. De ahí resultará la fundación del actual Warburg Institute de Londres. No es muy alentador imaginarse qué pudo haber quedado de la Warburg-Haus en las décadas de los 40 y 50.

32 Hofmann, W., Los fundamentos del arte moderno. Una introducción a sus formas simbólicas, trad. esp. Agustín Delgado y José Antonio Alemany, Barcelona, Ediciones Península, 1992, p. 7.

33 Ibidem.

34 Ibidem, véase en especial las pp. 373-98.

35 Como es sabido, la filosofía de las formas simbólicas fue concebida por Cassirer durante sus años en Hamburgo, en donde tuvo la oportunidad de frecuentar la Warburg-Haus. Blumenberg se referirá a ello en su discurso de 1974 en la Universidad de Heidelberg, pronunciado con motivo de la recepción del premio Kuno Fischer: "En Hamburgo estaba la biblioteca Warburg, dossier singular de cosas por descubrir. La teoría, si se puede decir así, de esa biblioteca y después del Instituto del mismo nombre, estaba en los tres volúmenes de la Filosofía de las formas simbólicas [1923-1929] de Cassirer. Ese sistema sobre la función simbólica constituía, bien mirado, la pieza final donde se realizaban las intenciones, implícitas o explícitas, de todo el neokantismo: considerar la tabla categorial de los objetos naturales solamente como un caso especial del sistema categorial de los objetos culturales, entre los cuales, al final, vuelven a emerger también los naturales, metódicamente dispuestos; pero gracias a los efectos de la red de formas simbólicas y de su estructura vertical se le abría a la teoría filosófica - o bien se destacaba e integraba de una manera nueva- un nuevo mundo de objetos y temas" (EC 
puesta explicativa a la dimensión genuinamente creadora, y no sólo representacional, de la experiencia humana:

[...] Partimos de la base de que al arte le es inherente una fuerza 'originariamente creativa y no meramente recreativa' [como en la teoría del conocimiento de Cassirer], ya que si esto no fuese cierto se abriría un vacío insalvable entre el arte 'figurativo' y el arte 'abstracto'. 36

Con esta premisa, el seguidor de Konrad Fiedler 37 y Ernst H. Gombrich, 38 trataba de dar cuenta de algunos de los "istmos" acaecidos en las primeras décadas del siglo XX: impresionismo, expresionismo, cubismo, futurismo, etc.

Blumenberg apenas si entra en el proceloso campo de las vanguardias artísticas del cambio de centuria, aunque en su conferencia mantiene la idea clave que atraviesa buena parte de los trabajos de Hofmann: la ruptura en el arte. ${ }^{39}$ La especificidad del planteamiento de Blumenberg consiste en proporcionar una interpretación ontológica de esta ruptura desde la exégesis histórico-filosófica de la Modernidad. Con ello introduce, a nuestro juicio, tres tesis fundamentales. La primera pasa por identificar en la ontología estética el nuevo lugar de fundamentación de la metafísica: "La obra [artística] no hace referencia a otro ser que le preceda, denotado y presentado por ella, sino que, en la porción de ser que le corresponde en el mundo del hombre, constituye algo originario" (NdN 57,75). En contrapartida, la segunda tesis hace de "la 'invención' [...] el acto significativo por antonomasia" (NdN 57, 76), el acto más humano que hay. Pero ello en el bienentendido de que la ruptura de la mímesis incide por igual en el arte y en la técnica. Ambos dominios, como Blumenberg señala, no estaban escindidos en la teoría griega antigua (mimética) del arte, dado que "[el arte] compendiaba todas las habilidades humanas conducentes a crear obras o a dar forma a la realidad, abarcando tanto lo 'artístico' como lo "artificial" ( $N d N 55,73)$. Dicho con más claridad, la Modernidad practica una doble ruptura: en la mímesis pictórica y en la mímesis técnica. Ni el arte ni la téc-

165,167). Para los detalles de la relación de Cassirer con el Instituto Warburg véase Silvia Ferretti, Il demone della memoria. Simbolo e tempo storico in Warburg, Cassirer, Panofsky, Marietti, Casale Monferrato, 1984, pp. 82-142.

36 Hofmann 1992, op. cit. (nota 32), pp. 7 y 71-4.

37 Arnold Gehlen, uno de los fundadores de la antropología filosófica alemana -junto con Helmuth Plessner- que tanto impacto habría de causar posteriormente en Blumenberg, se ha ocupado de Konrad Fiedler en su libro Imágenes de época. Sociología y estética de la pintura moderna [1960], traducción y prólogo de José Francisco Yvars y Vicente Jarque, Barcelona, Ediciones Península, 1994, pp. 97100. Gehlen también se ocupa en su libro de la obra artística de Paul Klee, pp. 159-76, a la que también se referirá Blumenberg, como veremos.

38 Hofmann 1992, op. cit. (nota 32), p. 7.

39 Véase también Hofmann, W., Une époque en rupture 1750-1830, Paris, Gallimard, 1995, en especial, pp. 7-45. 
nica deben en lo sucesivo imitar a la naturaleza. La tercera tesis de Blumenberg, que propiamente es la conclusión, afirma que gracias a esta erradicación de la mímesis -en sus dos niveles, técnico y artístico, insistimos- "se logró añadir al sujeto el atributo de creador" (NdN 57, 76). El hombre moderno, a diferencia del antiguo o del medieval, se convertirá en hombre creador en virtud de sus producciones artístico-técnicas, con las cuales intentará "probar la verdad de la imagen que tiene de sí mismo" (NdN 57, 75). El nuevo sujeto moderno, en suma, "ya no mira a la naturaleza, al cosmos, para extraer de ella el rango que le corresponde entre los seres, sino al mundo de las cosas surgido 'sola humana arte"' (NdN 59, 77-8).

La primera tesis -la nueva fundamentación de la metafísica en la ontología estética- será desarrollada por Blumenberg sobre todo en dos excepcionales trabajos de 1964: "Socrates y el 'objet ambigu'. La disputa de Paul Valéry con la tradición de la ontología del objeto estético" ( $P V A$ 285-323) y "El concepto de realidad y la posibilidad de la novela" ( $W b M$ 9-27, 29-48). La segunda y la tercera tesis -que la invención humana es el acto significativo por excelencia, gracias al cual el hombre moderno deviene en hombre creador- define la antropología de la Modernidad de Blumenberg, basada en el célebre principio de la autoafirmación humana. 40

El planteamiento general introducido por Blumenberg en su conferencia de 1956 consiste, por tanto, en hacer de la experiencia de la creación artístico-técnica el paradigma de autocomprensión del hombre durante la Modernidad. ${ }^{41}$ Partiendo

40 La primera vez que Blumenberg habla explícitamente de "autoafirmación" ["Selbstbehauptung"] es en su trabajo de habilitación Die ontologische Distanz [1950], y lo hace en relación con la pregunta cartesiana por la certeza. A ello le dedica todo un epígrafe «Die Selbstbehauptung der Vernunft vor der Gewißheitsfrage» $(o D \S 7)$. Cuatro años después volvió a tratar de la autoafirmación en unos términos parecidos en su reseña al libro de Helmo Dolch Kausalität im Verständnis des Theologen und der Begründer neuzeitlicher Physik. En esta reseña Blumenberg salía al paso de la interpretación que Doch hacía de la duda cartesiana como una "secularización" ["Säkularisierung"] (HD 202) de la pregunta por la salvación personal. Sin embargo, el verdadero desarrollo de la autoafirmación en la obra de Blumenberg vendrá con el artículo de 1962 "Ordnungsschwund und Selbstbehauptung. Über Weltverstehen und Weltverhalten im Werden der technischen Epoche" [1962] (OuS 37-57), preparatorio a su vez de Die Legitimität der Neuzeit [1966], el libro clave de Blumenberg sobre este argumento. Resulta difícil identificar, por otra parte, la fuente de inspiración última de este concepto. Quizá Blumenberg lo pudo obtener del famoso discurso de Heidegger pronunciado el 27 de mayo de 1933 con motivo de la toma de posesión del rectorado de la Universidad de Friburgo, que llevaba por título precisamente «La autoafirmación de la Universidad alemana» [Die Selbstbehauptung der deutschen Universität]. Este discurso lo encontramos citado en Die ontologische Distanz en la nota 7 (oD 218), y hubo de causar un gran impacto en Blumenberg. A él se ha referido monográficamente en $(H 733-$ 40, 599-608).

${ }^{41}$ En este sentido, podemos advertir una suerte de "secularización truncada" en el tratamiento temprano de Blumenberg de la Modernidad. A nuestro modo de ver, Blumenberg parece introducir en su conferencia una hábil transferencia de la teología medieval del "pensamiento de la creación" ["Schöpfungsgedanke"] (BPU 23) -que provenía de las Beiträge como una comprensión originaria del ser- al análisis histórico-filosófico de la época moderna. Esta transferencia ontológica sirve de base para la antropología del hombre creador, la primera antropología de la Modernidad de Blumenberg. 
de esta hipótesis, Blumenberg emprende la crónica de la eliminación del estatus normativo-ontológico de la naturaleza como referente para las producciones del arte y la técnica. En sus propias palabras:

[...] el pathos moderno de la producción auténticamente humana en el ámbito del arte y de la técnica surge de la oposición contra la tradición metafísica de la identidad de ser y naturaleza [...]. La determinación de la obra humana como una 'imitación de la naturaleza' ha sido consecuencia, justamente, de esa identidad. Claro que, aquí, se hace imprescindible una investigación más profunda de la base histórica de todo ello ( $N d N$ $64,83)$

Del intrincado recorrido por esa "base histórica", que culmina en el abandono del modelo mimético y la emergencia de una nueva metafísica, tan sólo nos vamos a fijar ahora en tres de los muchos casos aducidos por Blumenberg, los de Raoul Dufy [1877-1953], Franz Marc [1880-1916] y Paul Klee [1879-1940]. Con ellos aludiremos a la ruptura y posterior reedición de la mímesis pictórica.

\section{La ruptura de la mímesis en Raoul Dufy y Franz Marc}

En lo que respecta a Raoul Dufy, conviene tener presente que forma parte de una corriente artística denominada fauvismo. ${ }^{42}$ Aunque lo veremos después con más detenimiento, ahora podemos adelantar que el fauvismo comenzó a formarse en Francia en torno al año 1900 e incluía tres grupos bastante diferenciados. El primero estaba compuesto por Henri Matisse [1869-1954] y sus condiscípulos del estudio de Gustave Moreau y de la Acádemie Carrière: Albert Marquet [1875-1947] y Henri Manguin [1874-1949], entre otros. El segundo, en cambio, se había gestado en la escuela de Chatou, y destacaban sobre todo André Derain [1880-1954] y Maurice Vlamick [1876-1958]. Y en tercer lugar, el último grupo, el más tardío, provenía de El Havre y estaba formado por Emile Othon Friesz [1879-1949],

La Modernidad, en esta aproximación inicial, vendría a ser la época histórica en la que se produce un verdadero desplazamiento metafísico de Dios al hombre, en virtud del cual el hombre moderno habría tratado de gobernar su existencia con sus propias creaciones. Un caso ejemplar en este sentido sería para Blumenberg el de Nicolás de Cusa $(N d N)$.

42 Elderfield, J., El fauvismo, trad. española Juan Díaz de Atauri, Madrid, Alianza Editorial, 1993, p. 15. Una viva semblanza de Raoul Dufy en Jean-Paul Crespelle, Los fauves, Barcelona, Editorial Rauter, 1962, pp. 156-9. Es bastante probable que Blumenberg hubiera tenido conocimiento del fauvismo por primera vez a partir de los trabajos de Werner Hofmann, quizá con el citado artículo «'Manier' und 'Stil' in der Kunst des 20. Jahrhunderts», Studium Generale, 8, Berlin, 1955. Por otra parte, no sólo aquí se referirá Blumenberg al fauvismo de una manera significativa, también lo hará en la metaforología de los Paradigmen, como luego tendremos oportunidad de comprobar. Para el fauvismo véase además Hofmann 1992 (nota 32), pp. 219-23. 
George Braque [1882-1963] y, finalmente, Raoul Dufy. Todos los grupos eran liderados por Matisse, quien "fue al mismo tiempo jefe y eje de estos círculos". ${ }^{43}$ Franz Marc, por su lado, era uno de los principales representantes del expresionismo alemán, pero su obra se había visto muy influenciada tanto por el impresionismo como por el postimpresionismo franceses de la segunda mitad del siglo XIX.

En su conferencia de Munich, Blumenberg evocaba a Raoul Dufy y Franz Marc como la culminación de un proceso de reinterpretación de la naturaleza que se remontaría a los albores del siglo XIX. En este siglo, en opinión de Blumenberg, se iría imponiendo la visión de que la "naturaleza es el resultado de una serie de procesos mecánicos sin dirección alguna, de la condensación de la voraginosa materia primitiva, del juego conjunto de mutaciones esparcidas al azar y del hecho brutal de la lucha por la existencia" $(N d N 91,111)$. Así las cosas, no es de extrañar que la naturaleza acabase por producir repugnancia, hasta el punto de quedar invalidada como objeto estético: "¿Cómo podría el azar producir la sorprendente evidencia de lo bello?" (NdN 91, 112). Franz Marc y, sobre todo, Raoul Dufy serían, para Blumenberg, los dos mejores y más tardíos ejemplos de este exacerbado rechazo decimonónico de la naturaleza:

Así se puede entender lo hasta ahora impensable, a saber, que la naturaleza se haga odiosa, como nos lo atestigua Franz Marc: 'Los árboles, las flores, la tierra, todo me enseñaba, año tras año, su lado antipático, hasta que, de súbito, tuve plena conciencia del carácter odioso de la naturaleza, de su impureza'. El trasfondo ontológico lo reveló, con más precisión, el pintor francés Raoul Dufy, cuando a la objeción de que él, en el tema de la naturaleza, cortaba demasiado por lo sano, respondió: 'La naturaleza, señor mío, es una hipótesis [...]. (NdN 91, 112)

\section{Paul Klee y la renovación de la mímesis}

En lo que se refiere a Paul Klee, Blumenberg aludía a él con el objeto de cerrar apresuradamente su recorrido por la citada "base histórica". Si Parmigianino había inaugurado la conciencia artística de la capacidad creadora del hombre moderno -como una experiencia de la exuberacia inagotable de posibilidades-, Paul Klee intentó, por el contrario, extraer la necesidad de esa vorágine arbitraria de composibles, reactivando solapadamente, según Blumenberg, el denostado modelo mimético de la naturaleza:

Pienso en una obra tan paradigmática por la conciencia de sus impulsos como la de Paul Klee, en la que se revela cómo en el ámbito de la libre creación cristalizan, de improviso, estructuras donde se da a conocer, con una nueva fuerza de convicción, lo ancestral,

43 Elderfield 1993, op. cit. (nota 42), p. 15. 
lo que-siempre-ha-sido del fondo originario de la naturaleza. De este modo los nombres de los cuadros de Paul Klee no topan con la usual perplejidad de los artistas abstractos al tener que apelar a asociaciones con lo que nos es más familiar, sino que son actos de un reconocimiento estupefacto, donde, en definitiva, se puede anunciar que sólo un mundo ha realizado de una forma válida las posibilidades del ser y que la vía que se perdía en la infinitud de lo posible no era más que una huida de la esclavitud de la mímesis $(N d N$ 93, 113-4).

Blumenberg viene a proponer a Paul Klee 44 a modo de caso paradigmático del retorno hacia esa presunta originariedad ontológica, hasta el momento ocultada por la riqueza desmesurada del horizonte de posibilidades, y en la que los "infinitos mundos" destapados en la Modernidad no harían sino reflejar en última instancia "una única figura fundamental del ser" (NdN 93, 114), tal como dictaminaba la mímesis griega.

Intentamos ilustrar esta intrincada posición de Blumenberg con el siguiente autorretrato de Paul Klee de 1919, que lleva por título Ensimismamiento ["Versunkenheit"], y lo acompañamos además de una fotografía del artista realizada unos pocos años antes, un presunto "fondo originario":

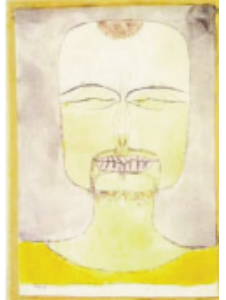

Figura 4. Paul Klee, Ensimismamiento, 1919

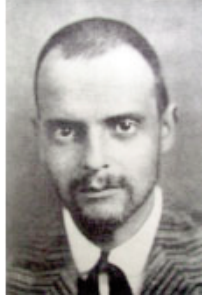

Figura 5. Fotografía de Paul Klee, 1912

Con esta inesperada apelación a la originariedad del ser, Blumenberg ofrecía una tentativa de solución provisional al problema de la mímesis y su puesta en suspenso a partir de la Modernidad. De esta forma sorprendente y un tanto abrupta Blumenberg cerraba su conferencia de 1956:

¿Pero no sería esto un círculo, que nos lleva de vuelta hacia el punto exacto de donde habíamos salido? Los signos de un círculo así asustan hoy día a muchos que temen que todos los atrevimientos hayan sido en vano. Es un error. Hay una diferencia decisiva entre aceptar lo dado como lo inevitable o reencontrarlo como un núcleo de evidencia en el ámbito de la posibilidad infinita y poder reconocerlo con libre asentimiento. De esto, en definitiva, se trataba: de una 'reesencialización de lo casual' [en palabras de Paul Klee]" (NdN 94, 114).

44 Una reconstrucción de la vida y obra de Paul Klee en Grohmann, W., Paul Klee, Genève, Trois Collines, 1969, pp. 25-100. En las pp. 124-49 hay información sobre la imaginería cósmica de Klee. Para sus dibujos véase Geelhaar, C., Klee dessins, Paris, Editions du Chêne, 1975, pp 7-34. 


\section{Una comprensión fauve de la metaforología temprana}

La ruptura moderna de la mímesis y la estética de la imaginación creadora 45 tendrán amplias resonancias en la metaforología desarrollada por Blumenberg en su primer libro, Paradigmen zur einer Metaphorologie [1960], sobre todo con lo que podemos denominar su temprana "metaforología fauve". En los Paradigmen se pone de relieve la profunda afinidad entre la metaforología y el arte moderno, en particular el de las vanguardias artísticas de finales del siglo XIX y comienzos del $\mathrm{XX}$. La metaforología comparte con estas vanguardias el problema de la ruptura entre figuración y abstracción, es decir, la suspensión de la mímesis en su sentido ontológico. La metaforología queda instalada en una tensión indisoluble entre la vida que pugna bajo la representación y la representación que se resiste a ser una reducción mimética de la vida. Como en el arte moderno, la metaforología refigura el mundo sin parecerse a él. Esta ruptura o distancia ontoepistemológica se agrava cuando el estudio de las metáforas es utilizado -como hace Blumenberg-a la manera de una herramienta para la reconstrucción histórica.

La principal dificultad estriba en que la verdad de las metáforas "no puede verificarse" (PM 23, 61). En palabras del propio Blumenberg: "en tanto en cuanto la 'verdad' es el producto de un procedimiento metódicamente guiado, o mejor, ha de serlo ex definitione [por definición], la metafórica no puede satisfacer esa pretensión, pues no sólo no dice la 'verdad estricta', sino que, en general, no dice la verdad" (PM 23, 61-2). Y en esto se parece al arte moderno. Pero también en la particularidad de que las metáforas, al igual que las creaciones artísticas, pese a que tengan un origen histórico bien preciso - que determina que su objeto sea "esencialmente histórico" (PM 23, 62-3), como afirma Blumenberg-su pretensión ontológica es la de alcanzar una validez independiente del tiempo, la de estar más allá de la historia y de autojustificarse sin su concurso. Sobre ello abunda Blumenberg en una compleja nota al pie que hallamos en los Paradigmen, y que sin duda merece citarse en toda su extensión:

Dicho sea de paso -aunque ello no tenga nada de accesorio-, estas consideraciones arrojan luz sobre el significado actual del arte como 'la actividad auténticamente metafisica de esta vida' (Nietzsche), cosa propia de una época que en su omnímoda voluntad de comprensión y auto-comprensión histórica ha destruido casi en todas partes su naturalidad de expresión genuina, y se ha creado en su arte algo así como una reserva de ahistoricismo históricamente consciente, de acusado ucronismo, puesto en franquía por un consenso universal. El absoluto, que al hombre moderno parece salirle sobre todo al

45 Para más detalles sobre este particular véase Kray, R., «Mimesis exhaustiv. Die 'Lesbarkeit der Bilde' in metaphorologischer Hinsicht», Philosophische Rundschau, 43, 1995, pp. 242-53; Terzuolo, L. A., «Hans Blumenberg: per un'estetica del possibile», Fenomenologia e società, Causale Monferrato, 15, 1992, n. 1, pp. 167-85. 
encuentro en sus experiencias estéticas (al menos, si debemos creer a la floreciente metafísica del arte), se presenta aquí como aquello inmune al quebranto de la conciencia que reflexiona desde el punto de vista histórico. De ahí esa predilección -una predilección que raras veces distingue rigurosamente entre ingenuidad y refinamiento- por los fauves, en un sentido que transciende su consideración como escuela. El aprecio que una eventual 'metaforología' futura habrá de tener por el valor de testimonio de la fantasía productiva para nuestra época depende de la respuesta a la cuestión básica: si se ha conseguido semejante éxtasis de la situación histórico-reflexiva; si, en general, es posible conseguir ese éxtasis (PM 24, 62-3).

No es, por tanto, el arte en general el que se vuelve ejemplar para la metaforología temprana de Blumenberg, sino un tipo específico de arte: el fauvismo.

Veamos ahora en detalle en qué consiste este enigmático fauvismo con el objeto de comprender mejor tanto la predilección que pudo haber sentido Blumenberg por esta corriente pictórica como las razones últimas de su ejemplaridad para la metaforología.

\section{Excurso: el fauvismo en perspectiva histórica}

En las postrimerías del siglo XIX se había producido una oleada de manifestaciones artísticas precursoras del fauvismo. Su denominador común no sólo era la abierta y honda escisión con respecto al pasado más esplendoroso de las bellas artes, sino, y esto nos interesa aún más, su abandono de la objetividad realista. El impresionismo, por ejemplo, la primera de estas vanguardias, introducía una forma inédita de acercarse a la realidad, fielmente apegada a la visión singular del artista. 46 Una buena muestra de ello es el célebre cuadro de Claude Monet Impresión, sol naciente:

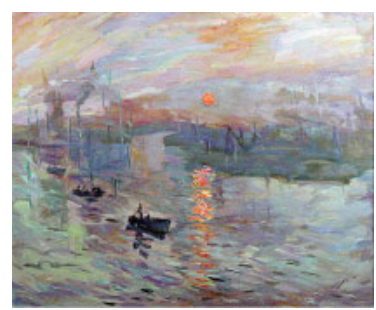

Figura 6. Claude Monet, Impresión, sol naciente, 1872

El fauvismo tuvo su primera gestación en Collioure, un pequeño puerto mediterráneo del sur de Francia, cercano a la frontera con España. Allí Henri Matisse y

46 Hofmann 1992, op. cit. (nota 32), pp. 141-206. 
André Derain pasaron el verano de 1905. El primer estilo fauve corresponde a la obra que ambos artistas realizaron en aquel apacible lugar. 47 De esta manera lo describe el historiador del arte John Elderfield:

El fauvismo surgió definitivamente en Collioure en el verano de 1905. [...] Matisse viajó al sur con su familia. En junio se reunió con ellos Derain. Ambos artistas iniciaron un período de cooperación asombrosamente productivo, que les llevó más allá de los confines del neoimpresionismo [...].48

El 28 de julio de ese mismo año, Derain enviaba una carta a su amigo Maurice Vlamick, en la que enumeraba cuidadosamente todo lo que estaba aprendiendo de su admirado maestro Matisse. ${ }^{49}$ De su enumeración, queremos destacar un punto que perfectamente podríamos asimilar también con la metaforología blumenberguiana: "es [...] un mundo que lleva el germen de su propia destrucción en cuanto se lleva al límite". 50 Mostramos a continuación uno de los muchos cuadros que Matisse y Derain pintaron en Collioure:

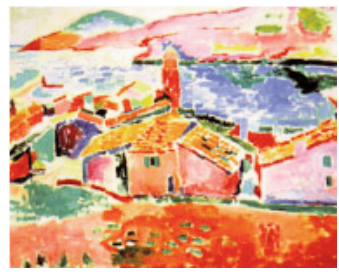

Figura 7. Henri Matisse, Vista de Collioure, 1905

Sin embargo, aquel verano de 1905 en Collioure era la gestación del estilo fauve. ${ }^{51} \mathrm{Su}$ episodio fundacional vendrá unos pocos meses después, en el otoño de ese mismo año. En palabras del historiador del arte Werner Hofmann:

En 1901 pudo verse en París una gran exposición de la obra de Van Gogh. Dos años más tarde, al morir Gauguin, su obra fue mostrada en el nuevo Salon d'Automne, en cuya fundación había participado Henri Matisse. Este salón vivió en 1905 la tempestuosa irrupción de una multitud de jóvenes artistas, cuya aparición tuvo un efecto inquietan-

\footnotetext{
47 Elderfield 1993, op. cit. (nota 42), pp. 15 y 59.

48 Ibidem, p. 55.

49 Elderfield llama la atención sobre "la grave y profesoral" imagen pública de Matisse: "Cuando quiso mostrar a sus padres que la carrera de pintor era respetable, Derain les presentó a Matisse para que se convencieran", ibidem, p. 16.

50 Carta de André Derain a Maurice Vlamick, 28/07/1905, citada por John Elderfield, ibidem, p. 55. Es inevitable pensar en las "metáforas explosivas" [Sprengmetaphorik] de Blumenberg (PM 179-84; LdN 558-638).

51 Para la formación del fauvismo véase Elderfield 1993, op. cit. (nota 42), en especial pp. 21-55.
} 
te. Ante una escultura de Marquet con reminiscencias del Quattrocento, un busto de mujer, el crítico Louis Vauxcelles, perturbado por su contraste, dice que se trata de 'Donatello en medio de las fieras' ['les fauves']. Con este término se refería a Henri Matisse, Georges Rouault, Maurice Vlamick y André Derain. En el transcurso de un año entraron también en la jaula de las 'fieras' Georges Braque y Raoul Dufy. 52

Merece la pena citar también la versión que John Elderfield elabora de ese evento a partir del testimonio de Matisse:

El bautizo del fauvismo es uno de los episodios más famosos del anecdotario del arte moderno. 'Exponíamos en el Salon d'Automne', recordaría Matisse más tarde, 'Derain, Manguin, Marquet, Puy y algunos otros habian colgado juntos sus obras en una de las grandes galerías. El escultor Marquet exponía un busto infantil de estilo italiano en el centro de esta misma sala. Cuando Vauxcelles entró, exclamó: ‘¡Vaya, Donatello entre las fieras!' ['Donatello au mileu des fauves'].53

Hofmann se equivoca, por tanto, al indicar que el busto que hubo suscitado la exclamación del influyente crítico de arte Louis Vauxcelles [1870-1943] era el de una mujer. Más bien era el de un niño, de ahí el comentario de Vauxcelles:

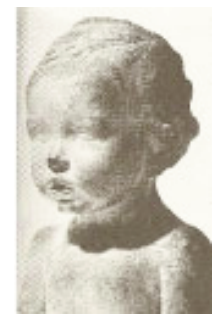

Figura 8. Albert Marquet, Retrato de Jean Baignères, 1905

Matisse exponía cuatro cuadros: El vestido japonés, La mujer del sombrero, El paseo y La ventana abierta. ${ }^{54}$ De todos ellos, fue este último el más controvertido de la exposición del Salon d'Automne.55 La singularidad de esta pintura estaba en

\footnotetext{
52 Hofmann 1992, op. cit., (nota 32) p. 220.

53 Elderfield 1993, op. cit. (nota 42), p. 50. En contraposición con el paradigma de "las fieras" o del "salvajismo" y todas sus connotaciones, esta corriente artística también podría haber tomado una denominación muy distinta bajo el modelo lúdico-infantil. Así nos lo sugiere Elderfield: "Muchos les llamaban 'les jeunes', y se les recriminaba que fueran como niños que jugaban con su caja nueva de colores", ibidem, p. 48.

54 Crespelle, J.-P., Los fauves, Barcelona, Editorial Rauter, 1962, p. 7.

55 Elderfield 1993, op. cit. (nota 42), p. 58. En su libro sobre los fauves, Jean-Paul Crespelle da cuenta de la relación de pintores y cuadros expuestos en la cage centrale del Salon d'Automne', omitimos
} 
la combinación de técnicas tanto impresionistas como postimpresionistas para el paisaje que se ve a través de la ventana, mientras que el interior de la habitación era realizado "a base de manchas toscamente aplicadas y zonas de tonos planos y bastante uniformes". 56

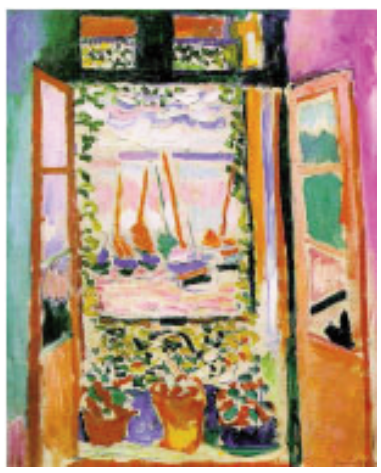

Figura 9. Henri Matisse, La ventana abierta, Collioure, 1905

Por su parte, Derain exponía cinco pinturas: un Autorretrato, tres paisajes de Collioure y Secando las velas. ${ }^{57}$ Mostramos a continuación esta última:

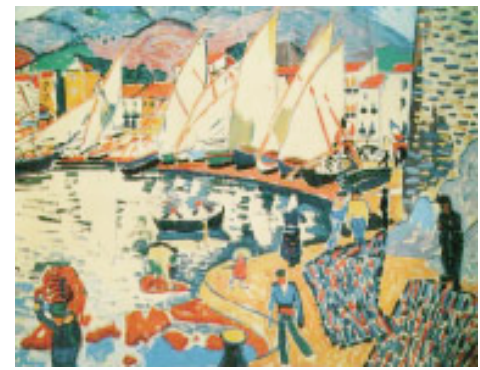

Figura 10. André Derain, Secando las velas, 1905

\footnotetext{
los cuadros de Matisse y Derain: "Manguin: La siesta, En el balcón, Bajo los árboles, Los alcornoques $y$ El prado [...]. Vlamick: El valle del Sena en Marly, La casa de mi Padre, El crepúsculo y El estanque de san Cucufate. Marquet: Anthéor, Menton, Agay y Las rocas rojas del Trayas. Valtat: Paisaje de Anthéor, dos Marinas, Retrato de mujer $e$ Interior. Puy: Matinal indolente, Paseo bajo los pinos, El camino modesto y Recuerdos de Concarneau. En aquel mismo Salón, pero en otras salas, Rouault presentaba varias obras de la serie Payasos y cómicos. Cézanne habia enviado cuadros de Bañistas, Vuillard La música, y el aduanero Rousseau El león devorando a un antílope. También exponian Jawlensky y Kandinsky, los coloristas rusos de Munich". Crespelle 1962, op. cit. (nota 54), p. 7.

56 Elderfield 1993, op. cit. (nota 42), p. 58.

57 Crespelle 1962, op. cit. (nota 54), p. 7.
} 
El fauvismo era, por tanto, más una consecuencia del escándalo que estas pinturas habían causado en el público del Salon d'Automne que un movimiento artístico con entidad propia y verdadera conciencia de sí. De este modo lo relata Elderfield:

Podría decirse que [el fauvismo] fue consecuencia de las reacciones de público y crítica ante la obra de aquellos artistas. [...] Los propios artistas no usaron ese nombre. 'Me dice Matisse que aún no tiene ni idea de lo que significa la palabra 'fauvismo", contaría más tarde Georges Duthuit. [...] [El movimiento fauve] se originó en el otoño de 1905, a partir del amplísimo interés público que suscitaron sus obras, y duró hasta el otoño de 1907 aproximadamente, cuando los críticos se dieron cuenta de que el movimiento estaba desintegrándose. 58

Así las cosas, el fauvismo llegó a su final tan sólo dos años después del verano en Collioure: "[...] cuando en 1907 Matisse y Derain siguieron cada uno su camino, el fauvismo se acabó". 59 Hofmann da cuenta de la clausura del movimiento fauve en estos otros términos:

Como movimiento, el fauvismo tuvo una breve duración. En 1907, Matisse abrió su propia escuela de pintura en París: el instinto organizado es transmitido como teoría. Ya en 1908 el grupo es atrapado por la resaca de Cézanne, que fue provocada un año antes a raíz de la gran exposición del pintor. [...] Uno de los fauves, Georges Braque, se convirtió, junto con Picasso, en fundador del 'cubismo'.60

\section{El fauvismo como metaforología estética del sentido}

Ahora no sólo estamos en condiciones de entender un poco mejor la posible predilección de Blumenberg por el fauvismo. También resulta más clara su afirmación de que el análisis histórico destruye por doquier la "naturalidad de expresión genui$n a "$ del arte, esa "reserva de ahistoricismo históricamente consciente" (PM 24, 62). El fauvismo, como decíamos, muestra el conflicto entre la vida que pugna bajo la representación y la representación que se resiste a ser una reducción mimética de la vida. Dicho de otro modo: el conflicto queda establecido entre la historia y la "fantasía productiva" (PM 24, 63). En consecuencia, el desideratum del "éxtasis de la situación histórico-reflexiva" (PM 24,63) que la metaforología quiere lograr en su bosquejo consiste en poder apresar el pasado pero también su correspondiente y sin-

\footnotetext{
58 Elderfield 1993, op. cit. (nota 42), p. 15.

59 Ibidem, p. 15. Para la herencia del fauvismo véanse, en especial, las pp. 153-63. El lector interesado podrá encontrar más información sobre la pintura posterior de Matisse en Carrà, M., Matisse. Desde la ruptura 'fauve' al intimismo 1904-1928, Barcelona, Editorial Noguer, 1976.

60 Hofmann 1992, op. cit. (nota 32), p. 223.
} 
gular reelaboración simbólica. La metaforología de los Paradigmen se instala así en esta deformante ruptura ontológica -típica del fauvismo- entre mundo vivido (o mundo acaecido) y mundo representado. En coherencia con ello, demanda la metafísica del objeto estético. La metaforología no será, por tanto, ni realista ni excluyente, pero servirá, sin embargo, a los propósitos de la exégesis histórica. Incluso podrá superarla ocasionalmente: "en forma de un realce e interpretación de los elementos expresivos artísticos, la tarea y metódica de la metaforología puede, pues, llevar más allá de la esfera histórico-objetiva" (PM 24, 63). En la metaforología, en suma, no queda invocada la verdad, sino el sentido. No tiene que ser cierta, sino significativa. 61

A esta interpretación podemos denominarla "la hipótesis estética de la metaforología". A nuestro modo de ver, explica en parte tanto el alcance limitado que Blumenberg le otorga inicialmente a su metaforología como la peculiaridad de su forma de proceder. Con esta hipótesis emerge una genuina metaforología "fauve". La metaforología de los Paradigmen coincide así con buena parte de los rasgos más llamativos del fauvismo. En la caracterización de Werner Hofmann del fauvismo: "frescura y despreocupación";62 "impetu antiformalista"; rechazo de "las reglas, métodos y sistemas racionales"; 63 "confianza en uno mismo" 64 y en la propia forma de hacer; voluntad de "fundirse con la realidad en un acto creador"; 65 un "anarquismo que no quiere dejarse encadenar por ninguna teoría"; 66 "el tema es secundario", lo importante "es la búsqueda del efecto más intenso"; 67 "de la obra de los patres llegan múltiples inspiraciones [...], éstas son adoptadas y reelaboradas de una manera notablemente asistemática". 68

De entre las múltiples coincidencias entre la metaforología de Paradigmen y el fauvismo queremos resaltar tres aspectos: su deliberado antiformalismo, su desembarazo ante la constricción de cualquier teoría y su libertad desprejuiciada a la hora de abordar la historia. 69

\footnotetext{
61 Esta problemática nos coloca en una posición muy incómoda, pues entendemos que también afecta a nuestro tratamiento histórico-filosófico de la metaforología blumenberguiana. Creemos coherente optar por una solución semejante a la de Blumenberg: no aspiramos a decir la verdad -o peor aún, la verdad última- sobre la metaforología sino, con más modestia, aspiramos sólo a decir algo sobre ella que pueda eventualmente resultar significativo. Nada más lejos, por tanto, que el espíritu cartesiano al que el propio Blumenberg se opone frontalmente en los Paradigmen (PM 7-8, 41-2).

62 Hofmann 1992, op. cit. (nota 32), p. 219.

63 Ibidem.

64 Ibidem.

65 Ibidem, p. 220.

66 Ibidem.

67 Ibidem, p. 221.

68 Ibidem.

${ }^{69}$ No es un tema menor el tratamiento de Blumenberg de la historia. Como en la comprensión lúdicoinfantil del fauvismo, en el que estos artistas no harían sido jugar como niños con su caja nueva de pinturas (Elderfield 1993, op. cit. (nota 42), p. 48), cabe dudar de la seriedad con la que Blumenberg
} 


\section{Metáfora y mito en el origen de los conceptos metafísicos}

En lo que respecta al artículo propiamente fundacional de la metaforología, "La luz como metáfora de la verdad: en el estadio previo a la formación de los conceptos filosóficos" [1957] ( $L a M$ 432-47), Blumenberg no apelaba tanto al paradigma pictórico de las vanguardias artísticas del cambio de centuria o al problema de la imitación de la naturaleza como a la tradición de los grandes maestros en la manipulación de la luz ( $\operatorname{LaM} 446,53$ ), en particular Rembrandt y Caravaggio. Sin embargo, en modo alguno constituía éste un paradigma pictórico dominante, si bien definía un referente estético de singular relevancia.

El punto de partida de la " "metaforología' filosófica" $($ LaM 432, 31) propuesta por Blumenberg en este artículo era la formación de las categorías de la metafísica, asimiladas, por un lado, a la creación de metáforas como "modos inmaduros y tentativos de expresión" (LaM 433,32) y, por otro, a la mitología: las "transformaciones miticas [...] de las conjeturas metafisicas encuentran su expresión en las metáforas" (LaM 432, 30).

Son cuatro, en consecuencia, los ejes del planteamiento inicial de la metaforología blumenberguiana: 1) la metáfora en tanto modo de expresión preconceptual; 2) la formación y evolución de las categorías metafísicas; 3) la conversión de las metafóricas en ontologías; y 4) su pauta mítica de transformación. Todo ello se especifica en el caso de la metaforología de la luz, que Blumenberg entiende, además, como una metaforología de la verdad:

Desde sus comienzos, la historia de la metafísica ha hecho uso de las metáforas de la luz con la finalidad de dar una referencia apropiada a su objeto último de estudio, que no dejaba apresarse en términos materiales. Una y otra vez, estas metáforas habían sido utilizadas para mostrar que hay algo más en el concepto de ser que una mera abstracción vacía; que constituye, por el contrario, el predicado más general y real que pueda obtenerse a partir de los entes. La relación de unidad y pluralidad, de lo absoluto y lo condicionado, de lo original y lo derivado... todo encontraba aquí su 'modelo' [...] (LaM 432, 31).

\footnotetext{
ha afrontado la historia, si no la habría convertido después de todo en un "mero" juego. A Blumenberg le resulta ajena, por ejemplo, una comprensión mesiánica del tiempo a la manera de Benjamin. Con mucho acierto Gianni Carchia ha caracterizado el tiempo histórico de Blumenberg como un "tiempo improductivo", que transcurre sin consecuencias, por así decir, como si en realidad no pasara nada, sea porque no causa efectos perdurables o porque no es sino una vacía reocupación funcional. Para más detalles véase la introducción de Carchia a la edición italiana de Lebenszweit und Weltzeit [1986], trad. it. de Bruno Argenton, Bologna, il Mulino, 1986, pp. 9-15: "Nelle analisi di Blumenberg, i fatti dello spirito si dispongono nella storia come all'interno di una superconscienza monadica, in cui il tempo non è veramente produttivo, ma è solo l'agente di un gioco infinito di variazioni caleidoscopiche, di scomposizioni e ricongiungimenti, riflessi e illusioni". Véase también Mazzini, M. «Strutture, soglie epocali, fratture. La construzione del senso del passato in Hans Blumenberg e Jan Assmann», Discipline Filosofiche, XVI, n. 1, Macerata, 2006, pp. 71-86.
} 
Las metáforas de la luz, con su "poder expresivo y sutil capacidad para el cambio" (LaM 432, 31), ofrecen el soporte adecuado para una reconstrucción de la historia de la metafísica, en tanto "las modificaciones de la base de la metáfora indican los cambios en la comprensión del mundo y del yo" (LaM 432, 31).70 Así las cosas, y bajo estas condiciones, Blumenberg propone en su artículo un sinuoso recorrido que va desde los filósofos presocráticos al teatro decimonónico. Nosotros vamos a atender en especial a la metáfora de la luz como una metáfora central de la metafísica cristiana, precisamente lo que Blumenberg daba por consabido en su reseña de 1987 del encuentro de Clovio con El Greco.

\section{Luz y palabra en la metafísica metafórica cristiana}

En la apresurada reconstrucción emprendida por Blumenberg en el artículo de 1957, el terminus a quo de la metafórica de la luz corresponde a una concepción dualista del mundo, ejemplarmente representada en el famoso poema de Parménides Del camino de la opinión, y luego asumida en la no menos célebre alegoría de la caverna de Platón. Blumenberg quiere mostrar que en esta primitiva "metafórica de la luz hay ya implícita una metafisica de la luz" (LaM 434, 33). Algo que se hace evidente, según Blumenberg, si reparamos en la circunstancia de que en el mundo griego antiguo la luz se autopresenta como la verdad del ser, y que lo hace además como transcendencia localizada. En el periodo helénico, la focalización de una luz transcendente se volverá un filosofema dominante: "la luz, que llena todo el cosmos como un medio, [...] es concentrada y objetivada a la manera de un polo metafísico" (LaM 434, 34). Ya en este período -y como en la singular alegoría del retrato de Clovio- "la luz se convierte en una metáfora para la 'salvación', para la inmortalidad" (LaM 435, 34). Blumenberg se refiere a ello como "el vuelo cósmico de la luz" (LaM 435,34) que abre una triple relación del hombre con respecto a la luz: mirar dentro de la luz, entrar en la luz y ser en la luz. La transcendencia de la luz se convierte así en un acontecimiento ontológico, en el que hará pie el neoplatonismo y la gnosis antigua ( $\operatorname{LaM} 435,34)$, pero también la tradición estoica. Con Cicerón dicho acontecimiento transcendental de la luz será míticamente transformado, por el contrario, en un evento interior, en el que la luz surgirá ahora desde

\footnotetext{
70 No podemos dejar de señalar que Blumenberg entiende el "estadio preliminar del concepto" como un "“estado de agregación', más vívido, más sensible a la inefabilidad y menos dominado por formas tradicionales" (LaM 432, 30). Con esta peculiar "inaccesible accesibilidad" (LaM 432, 31) entre el mundo y los conceptos que lo quieren expresar, Blumenberg se acerca a una inconceptuabilidad de carácter epistémico y antropológico, ya introducida en los Paradigmen y luego retomada dos décadas después en el apéndice de 1979 a Schiffbruch mit Zuschauer. Paradigma einer Daseinsmetapher (SZ 75-93, 97-117). Véase adicionalmente el póstumo de Blumenberg Theorie der Unbegrifflichkeit [2007] $(T d U)$.
} 
dentro del hombre como "luz natural", que se autoevidencia en los términos de una verdad moral inobjetable ( $\operatorname{LaM} 436,36)$.

Como envés necesario de la tradición metafórica de la luz, Blumenberg propone una paralela metafórica de las sombras, especificada en la larga singladura de la alegoría platónica de la caverna. Pero "la caverna no es simplemente el mundo opuesto a la luz" (LaM 437,36), también es el mundo de lo artificial, en el que los hombres pueden permanecer ajenos tanto al ser como a la verdad: "En Platón, [...] la liberación de las cadenas, la dolorosa reorientación y la ascensión, son los pasos hacia la desilusión que lleva a la noción crucial de paideia, que significa crear retrospectivamente una conciencia del mundo de la caverna como espera, una espera en la que el ser y la verdad estaban ausentes" (LaM 437, 37). No obstante, con el estoicismo ciceroniano, y luego con el neoplatonismo de Porfirio, la caverna alcanza un rango cósmico. Es decir, el interior y el exterior de la caverna coinciden, pues ambos constituyen dos formas simétricas en el orden tenebroso de la espera del ser. Tan sólo una luz que provenga del propio interior del hombre estará en condiciones de iluminar el mundo y producir la incontestable experiencia de la verdad: "Cicerón se ha familiarizado con la economía de la oscuridad [...], se puede decir que hubo creado una cierta afinidad entre su concepción de la caverna, en la que la naturaleza ha sido cambiada completamente en una res obscura, y toda certeza, que ahora pasa a ser realojada en la luz interna" (LaM 437, 37). Vendría a dar lo mismo, en suma, vivir en las entrañas de la tierra o en el diáfano espacio abierto de la superficie terrestre, una sombra semejante se cierne sobre el individuo, que debe extraer de su propio interior la luz de la verdad.

Tanto la transcendencia objetiva -(neo)platónica- como la inmanencia subjetiva -estoica- de la luz habrían preparado, en esta primera reconstrucción metaforológica de Blumenberg, el camino a la metafísica cristiana medieval. En este sentido, las angostas celdas del medioevo no son sino un sustituto de las oscuras cavernas de la Antigüedad:

Como cavernas individualizadas, las pequeñas habitaciones de las celdas monásticas se convierten, durante la Edad Media, en lugares en los que la verdad está abiertamente presente, una indicación de que ahora todo cabe ser esperado desde dentro. [...] En ellas uno puede esperar a la luz, tal como presupone la creencia en la gracia. Pero esta concepción se convierte al poco en una metáfora para el 'espacio interno de auto-posesión', tal como Montaigne entendía la 'caverna' (tanière) (LaM 437-8, 38). ${ }^{71}$

En la celda medieval -al igual que en el taller del Greco- la relación con el mundo va del interior al exterior. Por ello, en estos desabridos espacios monacales "la potencia creativa del hombre luce por vez primera" (LaM 438, 39). Pero al

${ }^{71}$ Los subrayados son de Blumenberg. 
mismo tiempo, es el lugar en el que se escenifica la conflictiva recepción cristiana de la metafórica de la luz, complicada por la recepción paralela de una metafórica de la palabra. De un lado, la creación ex nihilo propia del Cristianismo no permite ubicar ni focalizar la luz en el cosmos -a la manera del neoplatonismo- debido a que la luz creadora proveniente de Dios precede a todos los seres, y no se superpone con ellos. Además, la doctrina de la creación voluntaria de Dios -que involucra una suerte de decisión libre y puntual- no se aviene con facilidad con el carácter emanativo y naturalizado de una luz entendida como una suerte de creación continua ( $L a M$ 438-41, 41-3). Pero de otro lado, y en consonancia con el Antiguo Testamento, "la creación está basada en la palabra, y [...] la palabra siempre antecede a la creación" (LaM 442,47). En definitiva, la creación del mundo a partir del verbo, contrapuesta a una creación numinosa, hace de la realidad una sustancia significativa per se, de tipo lingüístico. Sin embargo, la palabra "no tiene la universalidad cósmica de la luz" (LaM 442-3, 48), y por añadidura, para poder ser escuchada y entendida, debe esperarse en un modo ciertamente diverso a como se esperaba al ser dentro de las oscuras cavernas de la Antigüedad. ${ }^{72}$ En la celda monacal, lugar por excelencia de la espera, se concitan, por tanto, la ciceroniana luz interior que habita en cada hombre y la palabra divina que irrumpe desde un desconocido exterior. Ambas, luz y palabra, constituyen la doble faz de la metafísica metafórica cristiana barruntada por Blumenberg, y cifrada con toda su ambiguedad en el retrato que El Greco hizo de Clovio.

Llegamos así a las cuatro metafóricas que dominan -en este artículo temprano de Blumenberg- la formación de la ontología medieval cristiana: una metafórica de la luz emparentada con una metafórica de la caverna, y una metafórica de la palabra emparentada con una metafórica de la escucha. Blumenberg lo sintetiza en dos bloques principales que a su vez dan forma, en última instancia, a una metafórica ontológica de la verdad: la metafórica de la visión y la metafórica de la escucha.

Para no extendernos más de lo necesario en los detalles, y con el propósito de ilustrar de manera rápida el fondo de la argumentación -que por lo demás Blumenberg aborda con mucha celeridad y de forma muy sintética, insistimos-consideramos oportuno traer a colación otra pintura aleccionadora del entramado histórico-filosófico abordado por Blumenberg en su pequeño artículo de 1957. Esta vez no pertenece al Greco, sino a Rembrandt, a quien Blumenberg cita de pasada en este trabajo como uno de los mejores ejemplos -junto con Caravaggio- de manipulación de la luz (LaM 446, 53). El festín de Baltasar, un cuadro pintado por Rembrandt en 1635, muestra ejemplarmente la conflictiva confluencia de la metafórica de la luz con la metafórica de la palabra en la ontología cristiana medieval:

\footnotetext{
72 Esta cuestión retornará, aunque de otro modo, en Matthäuspassion [1988]. Véase en especial ( $M p$ 67-82, 97-108).
} 


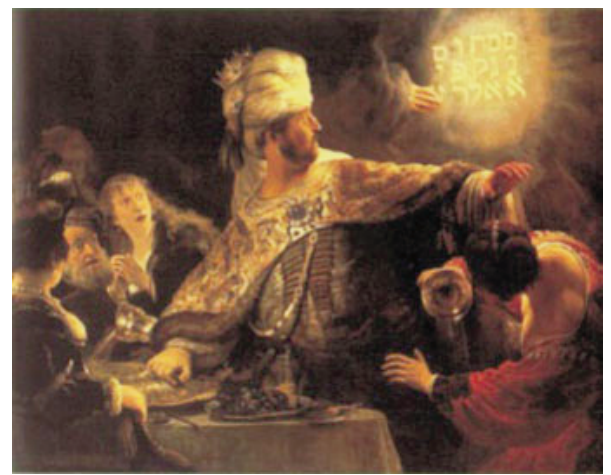

Figura 11. Rembrandt, El festín de Baltasar, 1635

En este cuadro se representa un pasaje bíblico del Antiguo Testamento, correspondiente a la profecía de Daniel:

El rey Baltasar hizo un gran convite a mil de los grandes de su corte: y cada uno bebía según su edad. Estando ya lleno de vino, mandó que trajeran los vasos de oro y de plata que había traído Nabucodonosor, su padre, del templo que hubo en Jesusalem, para que bebiesen con ellos el rey y los grandes de su corte, y sus mujeres y concubinas. ${ }^{73}$

Para asombro de los comensales, una mano fantasmagórica apareció de improviso y escribió una enigmática y radiante sentencia en el muro que se levantaba a sus espaldas: "mene mene teqel ufarsin". 74 Cuenta la Biblia (Dn, 5, 2-30) que ninguno de los presentes alcanzaba a dar un significado coherente a esta leyenda, por lo demás escrita en arameo. Tan sólo se identificaba una secuencia inconexa de palabras, que aisladamente tenían sentido, pero no en su conjunto: "contado" ("mene"), "pesado" ("tequel") y "dividido" ("ufarsin"). Así que, ante la estupefacción general, fue solicitada la presencia del profeta Daniel, quien las leyó e interpretó para el rey: "Dios ha contado los días de tu reinado y les ha señalado el límite; te ha pesado en la balanza, y te falta peso; tu reino se ha dividido y se lo entregan a medos y persas": 75

Entonces, por mandato del rey, fue Daniel vestido de púrpura, y le rodearon al cuello un collar de oro: y se hizo publicar que él tendría poder el tercero en su reino. Aquella misma noche mataron a Baltasar rey caldeo. Y Darío, que era medo, le sucedió en el reino, siendo de edad de sesenta y dos años. 76

73 La sagrada Biblia. Antiguo y Nuevo Testamento, trad. esp. de Felipe Scio. de S. Miguel, Nueva York, Sociedad Americana de la Biblia, 1832, p. 734.

74 Galindo Tixaire, A., «El arte de disfrazar la información», en Rev.. R. Acad. Cienc. Exact. Fís. Nat. Vol. 101, n. ${ }^{\circ} .2$ 2, 2007, p. 308.

75 Ibidem.

76 La sagrada Biblia, op. cit. (nota 73), p. 735. 
En este cuadro se escenifica perfectamente, en nuestra opinión, la tesis blumenberguiana de la doble génesis de la metafísica metafórica cristiana, es decir, la problemática convergencia de la metafórica de la luz -visión- con la metafórica de la palabra - escucha-, y en los términos, además, de una metafórica ontológica de la verdad: la luz del verbo que muestra la cegadora verdad.

Es éste, a nuestro juicio, otro de los muchos casos que vienen a mostrar las afinidades electivas entre la metaforología y la historia del arte, ${ }^{77}$ los múltiples paradigmas pictóricos de la metaforología temprana de Blumenberg.

\section{Listado de abreviaturas}

(AM) Arbeit am Mythos [1979], Frankfurt am Main, Suhrkamp, 2006. Trad. esp. Pedro Madrigal, Trabajo sobre el mito, Barcelona, Editorial Paidós, 2003.

(BiG) Begriffe in Geschichten, Frankfurt am Main, Suhrkamp, 1998. Trad esp. César G. Cantón y Daniel Innerarity, Conceptos en historias, Madrid, Editorial Síntesis, 2003.

(BPU) Beiträge zum Problem der Ursprünglichkeit der mittelalterlich-scholastischen Ontologie, Tesis doctoral, Christian-Albrechts-Universität zu Kiel, 1947. $(D d H)$ "Das dritte Höhlengleichnis", Filosofia, 11, 1960, pp. 705-22.

(dS) Die Sorge geht über den Fluß, Frankfurt am Main, Suhrkamp, 1987. Trad. esp. Jorge Vigil y Manuel García Serrano, La inquietud que atraviesa el río. Ensayo sobre la metáfora [1987], Ediciones Península, Barcelona, 1992.

$(d V A)$ "Die Vorbereitung der Aufklärung als Rechtfertigung der theoretischen Neugierde", en Hugo Friedrich, Fritz Schalk (eds.), Europäische Aufklärung. Herbert Dieckmann zum 60. Geburtstag, Fink, München, 1967, pp. 23-45.

(EC) "Ernst Cassirers gedenkend. Rede bei der Entgegennahme des Kuno FischerPreises der Universität Heidelberg im Juli 1974", en Revue Internationale de Philosophie 28, 1974, pp. 456-463. Recopilado en Wirklichkeiten in denen wir leben. Aufsätze und eine Rede, Reclam, Stuttgart, 1981, pp. 163-72. Trad. esp. de Pedro Madrigal, Las realidades en las que vivimos, Paidós ICE/UAB, Barcelona, 1999.

(EmS) Ein mögliches Selbstverständnis. Aus dem Nachlaß, Stuttgart, Reclam, 1997.

Trad. esp. César González Cantón y Daniel Innerarity, La posibilidad de comprenderse, Madrid, Síntesis, 2002.

(EuR) "Epochenschwelle und Rezeption", Philosophische Rundschau 6, 1958, pp. 94-120.

77 El lector interesado podrá encontrar más detalles en Fragio, A., «La ciencia en el infierno: Blumenberg y el hombre-árbol de 'El jardín de las delicias'», Escritura e Imagen, vol. 6, Universidad Complutense de Madrid, 2010, pp. 147-74. 
(H) Höhlenausgänge [1989], Frankfurt am Main, Suhrkamp, 1996. Trad. esp. José Luis Arántegui, Salidas de la caverna, Madrid, Antonio Machado Libros, 2004. (HD) "Helmo Dolch: Kausalität im Verständnis des Theologen und der Begründer neuzeitlicher Physik", Philosophische Rundschau 3, 1955, 3/4, 198-208.

(Marg) "Marginalien zur theologischen Logik Rudolf Bultmanns", Philosophische Rundschau 2, 1954/55, 3/4, pp. 121-40.

(Mp) Matthäuspassion, Frankfurt am Main, Suhrkamp, 1988.

$(N d N)$ " "Nachahmung der Natur'. Zur Vorgeschichte der Idee des schöpferischen Menschen", en Studium Generale, 10, 5, 1957, pp. 266-83. Recopilado en Wirklichkeiten in denen wir leben. Aufsätze und eine Rede, Reclam, Stuttgart, 1981, pp. 55-103. Trad. esp. de Pedro Madrigal, Las realidades en las que vivimos, Paidós ICE/UAB, Barcelona, 1999.

(LaM) "Licht als Metapher der Wahrheit. Im Vorfeld der philosophischen Begriffsbildung”, en Studium Generale, 10, 7, 1957, pp. 432-47. Trad. ingl. de Joel Anderson, "Light as a Metaphor for Truth. At the Preliminary Stage of Philosophical Concept Formation”, en David Michael Levin (ed.), Modernity and the Hegemony of Vision, University of California Press, Berkeley, 1993, pp. 30-62.

(LdN) Die Legitimität der Neuzeit, [1966], Frankfurt am Main, Suhrkamp, 1996. Trad. esp. Pedro Madrigal, La legitimación de la Modernidad, Valencia, Pretextos, 2008.

(LW) Lebenszeit und Weltzeit [1986], Frankfurt am Main, Suhrkamp, 2001. Trad. esp. Manuel Canet, Tiempo de la vida y tiempo del mundo [1986], Valencia, Pretextos, 2007.

(oD) Die ontologische Distanz. Eine Untersuchung über die Krisis der Phänomenologie Husserls, Trabajo de habilitación, Christian-AlbrechtsUniversität zu Kiel, 1950.

$(O u S)$ "Ordnungsschwund und Selbstbehauptung. Über Weltverstehen und Weltverhalten ím Werden der technischen Epoche”, en Helmut Kuhn, Franz Wiedmann (eds.): Das Problem der Ordnung (VI. Deutscher Kongress für Philosophie, München 1960), Meisenhelm am Glan, Hain 1962, pp. 37-57.

(PM) Paradigmen zu einer Metaphorologie [1960], Frankfurt am Main, Suhrkamp, 1998. Trad. esp. de Jorge Pérez de Tudela Velasco, Paradigmas para una metaforología, Madrid, Trotta, 2003.

(SZ) Schiffbruch mit Zuschauer. Paradigma einer Daseinsmetapher [1979], Frankfurt am Main, Suhrkamp, 1988. Trad. esp. Jorge Vigil, “Aproximación a una teoría de la inconceptualidad“ en Hans Blumenberg, Naufragio con espectador. Paradigma de una metáfora de la existencia [1979], Madrid, Visor, 1995. (TdU) Theorie der Unbegrifflichkeit, Suhrkamp, Frankfurt am Main, 2007.

$(V d N)$ "Die Vorbereitung der Neuzeit", Philosophische Rundschau 9, 1962, 2/3, pp. 81-133. 
$(W b M)$ "Wirklichkeitsbegriff und Möglichkeit des Romans", en Hans Robert Jauss (ed.), Nachahmung und Illusion (Poetik und Hermeneutik, I), Fink, München, 1964, pp. 9-27. Publicado de nuevo en Bruno Hillebrand (ed.), Zur Struktur des Romans, Wissenschaftliche Buchgesellschaft, Darmstadt, 1978, pp. 238-267; y en Klaus-Detlev Müller (ed.), Bürgerlicher Realismus. Grundlagen und Interpretationen, Athenäum, Königsstein/Taunus, 1981, pp. 39-56. Trad. ingl. de David Henry Wilson, "The Concept of Reality and the Possibility of the Novel", Richard E. Amacher y Victor Lange (eds.), New Perspectives in German Literary Criticism. A Collection of Essays, Princeton University Press, Princeton, 1979, pp. 29-48. 